\title{
Prevalence and Awareness of Hypertension among Adults and its Related Risk Factors
}

Basant Maharjan'1

${ }^{1}$ Community Health Development Program, Public Health Concern Trust (phect-NEPAL) Kathmandu, Nepal.

\begin{abstract}
Background: Hypertension is a modifiable risk factor for cardiovascular diseases. Various studies conducted in the world showed high prevalence of hypertension, which is in increasing trend in Nepal also. The aim of this study was to assess hypertension status and risk behaviours among adult population in Kirtipur Municipality.

Methods: A cross sectional descriptive study was conducted among 580 adults of age 20 - 59 from December 2015 to April 2016. Data was collected by observation method to determine hypertension prevalence and Body Mass Index. Questionnaire was used to assess exposure to the risk factors.

Results: Among all hypertension prevalence was $37.0 \%$ (215 out of 580). The prevalence was $41.6 \%$ (110 out of 264) among male and 32.2\% (105 out of 316) among female ( $\mathrm{P}<0.03$ at $95 \% \mathrm{CI}$ ). Among 215 hypertensives, 37.2\% were not aware about themselves having hypertension. Within last 12 months, 453 (78.1\%) participants had checked their blood pressure. Proportion of hypertension was increasing with higher BMI and advancing age. Among all, 136 (23.7\%) were current smokers, and $58.1 \%$ among them had hypertension.

Conclusions: This study indicated that hypertension prevalence was high among adults in Kirtipur municipality. Prevalence of smoking was also high, and among them hypertension prevalence was very high. About one-third participants with hypertension were not aware that they had hypertension. Habit of doing regular physical exercise was very low.

Keywords: Body mass index; hypertension prevalence; smoking.
\end{abstract}

\section{INTRODUCTION}

WHO estimates that non-communicable diseases were responsible for more than $68 \%$ of deaths in $2012 .{ }^{1}$ Hypertension, obesity, physical inactivity, smoking are some major cardiovascular risk factors ${ }^{2}$ and if hypertension left uncontrolled, it causes stroke, myocardial infarction, cardiac failure, renal failure and blindness. ${ }^{1}$ A report of 1996 stated arterial hypertension related cardiovascular diseases were responsible for nearly $20 \%$ of all deaths world-wide. ${ }^{3}$ Aging and behavioural factors, such as unhealthy diet, lack of physical activity, excess weight and stress attribute in increasing prevalence of hypertension. ${ }^{4} \mathrm{~A}$ review report stated prevalence of hypertension in Nepal ranges from $18.8 \%$ to $41.8 \% .^{5}$ Various studies in different places and time showed different prevalence. ${ }^{6-11}$ Studies also showed many people having high blood pressure did not know they have hypertension. ${ }^{6,12}$

The study was aimed to measure hypertension prevalence among adults in Kirtipur municipality, and to explore the risk behaviours of people.

\section{METHODS}

This was a cross sectional study conducted among adult population of age between 20 and 59 years in Kirtipur municipality. Data was collected from December 2015 to April 2016. Ethical approval from Nepal Health Research Council was taken prior to start the study. Likewise, permission from Kirtpur Municipality Office was taken. Informed consent was sought from the participants before data collection. A total of 580 participants were selected from four selected wards of the municipality. At first, four wards out of 19 were selected randomly, and required number of households was selected on basis of proportionate probability sampling from each selected ward. One eligible member from each selected household was randomly chosen as participant. The people who have been temporarily residing as tenant in the selected households and the family members who
DOI: http://dx.doi.org/10.3126/ inhrc.v15i3.18848
Correspondence: Dr Basant Maharjan, Community Health Development Program, Public Health Concern Trust (phect-NEPAL) Kathmandu, Nepal. Email: basant06maharian@ yahoo.com, Phone : +977 9841276057. 
were not present at the time of data collection were excluded from selection list.

An observation format was used to record anthropometric information to calculate Body Mass Index (BMI) and blood pressure readings. Blood pressure was measured adopting guidelines recommended by the WHO STEP Surveillance, Training and Practical Guides to Physical Measurement Manual. ${ }^{13}$

A semi-structured questionnaire was used to assess knowledge about effects of hypertension and exposure to risk factors such as smoking, alcohol consumption, and physical activities. Prevalence of smoking was assessed on the basis of if the participants have smoked at least once within last seven days, use of alcohol was assessed on basis of if they have had any alcoholic beverage within last 12 months, and physical exercise assessed on basis of if they did exercises once or more in a week for at least 10 minutes at a time within last four weeks. Blood pressure was measured using digital automatic blood pressure monitor (OMRON, Japan), and recorded blood pressure was categorized according to the blood pressure classification of $7^{\text {th }}$ Report of Joint National Commission which classifies level of blood pressure as: normal (< $120 / 80 \mathrm{mmHg}$ ), pre-hypertension (SBP 120-139 and / or DBP 80-89 $\mathrm{mmHg}$ ), stage 1 hypertension (SBP 140-159 and / or DBP 90-99 $\mathrm{mmHg}$ ) and stage 2 hypertension (SBP $=/>160$ and $/$ or DBP $=/>100 \mathrm{mmHg}) .{ }^{2}$ Observed SBP level $=/>140 \mathrm{mmHg}$ and $/$ or DBP $=/>90 \mathrm{mmHg}$ was considered as existence of hypertension, ${ }^{1}$ those who reported as they are on anti-hypertensive medications currently were also considered as previously diagnosed hypertensive.

A digital weighting scale (Tanita, Japan) was used to measure body weight and a statute height measuring scale (Bio-Plus, India) was used to measure body height. The BMI was interpreted on basis of the BMI Classification of Global Database on Body Mass Index, $\mathrm{WHO}^{14}$ and BIM Index for Asian Population. ${ }^{15}$ The data was entered into the SPSS 17 package, and descriptive statistics for frequencies, percentage and correlation were calculated for relevant variables.

\section{RESULTS}

Among 580 participants, 314 (54.5\%) were female and 264 (45.5\%) were male, and majority $(39.5 \%)$ was in age group of 30 - 39 and majority (73.5\%) was Newar. Of total $453(78.1 \%)$ had checked their BP within last 12 months, and the practice proportion is higher among female and illiterate or participants with non-formal education (Table 1).

\begin{tabular}{|c|c|c|c|}
\hline \multirow[t]{2}{*}{ Gender } & \multicolumn{2}{|c|}{$\begin{array}{l}\text { BP checked } \\
\text { within last } 12 \\
\text { months }\end{array}$} & \multirow[t]{2}{*}{ Total } \\
\hline & Yes & No & \\
\hline Female & 255 (80.7\%) & 61 & 316 \\
\hline Male & $198(75.3 \%)$ & 66 & 264 \\
\hline Total & 453 (78.1\%) & 217 & 580 \\
\hline \multicolumn{4}{|l|}{ Education status } \\
\hline $\begin{array}{l}\text { Illiterate or no formal } \\
\text { education }\end{array}$ & $144(86.7 \%)$ & 23 & 166 \\
\hline School level & 97 (78.2\%) & 27 & 124 \\
\hline $\begin{array}{l}\text { Higher secondary or } \\
\text { above }\end{array}$ & 212 (73.1\%) & 78 & 290 \\
\hline
\end{tabular}

On basis of JNC 7 category for BP classification, 235 (40.5\%) were fall under Normal BP, 130 (22.4\%) in PreHypertensive stage, 194 (33.4\%) in Stage I Hypertension and 21 (3.6\%) in Stage II Hypertension (Table 2).

\begin{tabular}{|c|c|c|c|c|c|}
\hline \multirow[t]{2}{*}{$\begin{array}{l}\text { Age } \\
\text { Group }\end{array}$} & \multicolumn{5}{|c|}{ Blood Pressure Status } \\
\hline & Normal & $\begin{array}{r}\text { Pre } \\
\text { HTN }\end{array}$ & $\begin{array}{r}\text { HTN } \\
\text { Stage I }\end{array}$ & $\begin{array}{r}\text { HTN } \\
\text { Stage }\end{array}$ & Total \\
\hline $20-29$ & 16 & 3 & 1 & 0 & 20 \\
\hline $30-39$ & 156 & 47 & 21 & 5 & 229 \\
\hline $40-49$ & 45 & 47 & 81 & 3 & 176 \\
\hline $50-59$ & 18 & 33 & 91 & 13 & 155 \\
\hline Total & $\begin{array}{r}235 \\
(40.5 \%)\end{array}$ & $\begin{array}{r}130 \\
(22.4 \%)\end{array}$ & $\begin{array}{r}194 \\
(33.4 \%)\end{array}$ & $\begin{array}{r}21 \\
(3.6 \%)\end{array}$ & 580 \\
\hline
\end{tabular}

( ${ }^{*}$ Normal - SBP < 120 and DBP < 80 mmHg; Pre HTN - SBP 120 139 or DBP 80 - 89 mmHg; Stage I HTN - SBP 140 - 159 or DBP 90 - $99 \mathrm{mmHg}$; Stage II HTN - SBP = / > 160 or $D B P=/>100 \mathrm{mmHg}$ )

Among total, 215 (37.0\%) were found with hypertension. The prevalence was $32.2 \%$ among female and $41.6 \%$ among male ( $P<0.03$ at $5 \%$ level of significance). The rate was highest $(59.1 \%)$ among age group 50 - 59 (Table 3). Among 215 hypertensive, 80 (37.2\%) did not know that they have high blood pressure.

Among all, 514 (88.6\%) perceived that raised BP should be kept in control, and out of them $89.9 \%$ responded as otherwise it may cause paralysis or problem in brain, $61.8 \%$ as heart attack and $25.3 \%$ as problem in kidney. Out of 163 participants who told as they have high blood pressure, $61.3 \%$ responded they are on allopathic medication and $14.1 \%$ on alternative medication. 


\begin{tabular}{|c|c|c|c|c|c|c|c|c|}
\hline \multirow[t]{2}{*}{$\begin{array}{l}\text { Age } \\
\text { group }\end{array}$} & \multicolumn{2}{|c|}{ HTN Status Male } & \multicolumn{2}{|c|}{ HTN Status Female } & \multicolumn{2}{|c|}{ HTN Status Combined } & \multirow{2}{*}{ Total } & \multirow{2}{*}{$\begin{array}{r}\text { Confidence } \\
\text { level } 95 \%\end{array}$} \\
\hline & Yes * & No & Yes * & No & Yes * & No & & \\
\hline $20-29$ & 0 & 5 & 1 & 14 & $1(5 \%)$ & 19 & 20 & \\
\hline $30-39$ & 15 & 87 & 11 & 116 & 26 (11.3\%) & 203 & 229 & Fisher Exact \\
\hline $40-49$ & 40 & 42 & 44 & 50 & $84(47.7 \%)$ & 92 & 176 & $P=<0.001$ \\
\hline $50-59$ & 55 & 20 & 49 & 31 & 104 (59.1\%) & 51 & 155 & \\
\hline Total & $\begin{array}{r}110(41,6 \% \\
\text { among male) }\end{array}$ & 154 & $\begin{array}{r}105 \\
\text { (32,2\% among } \\
\text { female }\end{array}$ & 211 & $\begin{array}{l}215(37.0 \% \\
\text { among total) }\end{array}$ & 365 & 580 & $\begin{array}{l}\text { Male to } \\
\text { Female; } \\
\mathrm{P}<0.03\end{array}$ \\
\hline
\end{tabular}

* $S B P=>140 \mathrm{mmHg}$ and or $\mathrm{DBP}=>90 \mathrm{mmHg}$

Table 4. Hypertension status by BMI.

BMI

High Blood Pressure

Total

Yes*

No

$\mathrm{N}=580$

BMI classification of Global Database on Body Mass Index, WHO ${ }^{14}$

\begin{tabular}{lccc} 
Below $(<18.5)$ & $1(10.0 \%)$ & $9(90 \%)$ & 10 \\
Normal $(18.5-24.9)$ & $49(20.9 \%)$ & $185(79.1 \%)$ & 234 \\
Pre obese $(25-29.9)$ & $125(44.9 \%)$ & $153(55.1 \%)$ & 278 \\
Obese $(=/>30.0)$ & $40(68.9 \%)$ & $18(31.1 \%)$ & 58 \\
BMI classification for Asian Population ${ }^{13}$ & & & 10 \\
Under weight $(<18.5)$ & $1(10.0 \%)$ & $9(90 \%)$ & 151 \\
Acceptable / increasing risk (18.5 - 23.0) & $28(18.5 \%)$ & $123(81.5 \%)$ & 269 \\
Increased risk $(23-27.5)$ & $96(35.7 \%)$ & $173(64.3 \%)$ & 150 \\
\hline Higher high risk $(=>27.5)$ & $90(60.0 \%)$ & $60(40.0 \%)$ & \\
\hline
\end{tabular}

* $S B P=>140 \mathrm{mmHg}$ and or $D B P=>90 \mathrm{mmHg}$

Among all, on basis of BMI classification of Global Database, WHO, 58 (10.0\%) were obese and 278 (47.9\%) were in pre obese state of BMI. Out of 58 obese and 278 pre obese, $68.9 \%$ and $44.9 \%$ respectively have hypertension. Likewise, on basis of BMI classification recommended for Asian Population, out of total, 150 (25.9\%) were in higher high risk group and 269 (46.4\%) were in increased risk group. Among higher high risk group and increased risk group, $60.0 \%$ and 35.7\% respectively have hypertension (Table 4).

\begin{tabular}{|c|c|c|c|}
\hline \multirow{2}{*}{ Smoking status } & \multicolumn{2}{|c|}{ High Blood Pressure } & \multirow{2}{*}{ Total } \\
\hline & Yes & No & \\
\hline Yes & 79 (58.1\%) & 57 & $\begin{array}{c}136 \\
(23.5 \%)\end{array}$ \\
\hline No & $112(27.4 \%)$ & 296 & 408 \\
\hline Used to smoke* & $24(66.7 \%)$ & 12 & 36 \\
\hline Total & 215 & 365 & 580 \\
\hline
\end{tabular}

Out of 580 participants, 136 (23.5\%) were current smokers, and among them $58.1 \%$ have hypertension whereas the prevalence was $27.4 \%$ among non-smokers (Table 5). Among total, 171 (29.5\%) never consumed alcoholic beverage in last 12 months and other 409 (70.5\%) had consumed alcoholic beverage at least one occasion more during the period. Only 158 (27.2\%) responded as they do physical exercise and out of them 53 (33.3\%) had responded as they do regular ( $=/$ or $>5$ days in a week) physical exercise.

\section{DISCUSSION}

Out of 580 participants, it was found that about 453 (78.1\%) participants have checked their BP in last 12 months which was only $57.3 \%$ in a national level survey conducted in Nepal in 2013.9 The rate was higher in women $(80.7 \%)$ in compare to men $(75.3 \%)$. The practice of checking BP was found more among illiterate or without formal education (86.7\%) in compare to those having higher-level education (73.1\%) and school level formal education (78.2\%). 
On basis of JNC 7 category for BP classification, 130 (22.4\%) were in Pre Hypertensive stage, which is high risk ratio (2.5 among women and 1.6 among men) for cardiovascular diseases in compare to normal $\mathrm{BP}^{16}$ which was much lower than a community study in 2015 that showed $46.6 \%$ pre-hypertension. ${ }^{12}$ Among all, 215 (37.0\%) participants have raised blood pressure $(\mathrm{SBP}=/>140$ or $\mathrm{DBP}=/>90 \mathrm{mmHg}$ ), which was $32.2 \%$ among women and among men it was $41.6 \%$. The difference was significant at $5 \%$ significance level $(P<0.03)$. The prevalence is higher than a national level study of 2015 which reported $26 \%$ prevalence of hypertension among Nepalese adults (Men $31 \%$ and women $21 \%)^{9}$, and a rural community study in 2015 which showed $20.5 \%$ prevalence (Male $30.6 \%$ and Female 13.8\%). ${ }^{12}$

The study found that prevalence of hypertension is increasing with advancing of age (5\% in age group 20 $29 ; 11.3 \%$ in age group $30-39 ; 47.7 \%$ in age group $40-49$; $59.1 \%$ in age group 50 -59). The difference was highly significant at $5 \%$ level of significance $(P<0.001)$. The prevalence among age group 50 - 59 years old was slight lower than a study conducted in Banepa municipality in 2012, which showed $49.4 \%$ among age group 50 - 64 years $^{10}$ but higher than one another study of municipalities of Kathmandu that showed $45.0 \%$ among age group $50-59$, and almost similar among the age group below 30 years old (5.9\%) and among 40 - 49 years group (47.3\%). ${ }^{11}$ The prevalence among age group below 30 years was much more lower than one another study of 2010 that showed prevalence of $11.1 \% .{ }^{17}$

Among 215 participants having high blood pressure currently, 80 (37.20\%) were not aware that they have high BP. The data is higher in compare to the 7th Report of the JNC on Prevention, Detection, Evaluation, and Treatment of High Blood Pressure which stated it was approximately 30 percent $^{2}$ and is much less than a study of Dhulikhel that showed $69.9 \%$ of hypertensive were unaware of their hypertensive status ${ }^{14}$ and almost similar (39.1\%) to a study of city malls in Kathmandu that showed only $39.13 \% .{ }^{18}$ Out of 112 participants who have never checked BP in last 12 months, 24 (11.2\%) have hypertension and did not know about their hypertensive state and who responded as they are hypertensive (163 participants), 100 (61.3\%) had responded they are currently on allopathic medication. However medication history was collected on basis of the information provided by the participants without further verification.

Among all, 234 (40.4\%) have normal BMI score, which is very less than the report of STEPS National Survey Nepal 2013, i. e. $67.9 \% .{ }^{9}$ About $47.9 \%$ participants were in pre-obese state and $10.0 \%$ in obese category, which were $17.7 \%$ and $4.0 \%$ respectively in the same national level study. The prevalence of hypertension was found increasing with higher the BMI score $(20.9 \%$ among those with normal BMI score, $44.9 \%$ among pre-obese and $68.9 \%$ among obese). On the basis of the BMI Index recommended for Asian Population ${ }^{15}$ as well, proportions of hypertension were increasing with higher the BMI (18.5 $\%$ among acceptable group, $35.7 \%$ among increasing risk group and $60.0 \%$ among higher high risk group).

Among total, 136 (23.5\%) were current smokers and the rate is slight higher than the national survey in 2013 which showed it was $18.5 \%{ }^{9}$ Likewise, a study in three municipalities of Kathmandu in 2016 showed only $19.9 \%$ prevalence of smoking ${ }^{11}$ and $28.6 \%$ in a rural community among 20 - 50 years adults. ${ }^{8}$ Among the current smokers, 79 (58.1\%) were found with hypertension whereas it was only $27.4 \%$ among the non-smokers (112 out of 408 ).

Of total, 409 (70.5\%) consume alcoholic drinks with various consumption frequencies (some with less than one time per month in average to more than four times per month average). A study of other municipalities in Kathmandu reported prevalence of alcohol use was $27.0 \%$ only ${ }^{11}$ and in a rural community in Sindhupalchowk showed $47.8 \% .^{8}$ The high prevalence of alcohol use may be due to socio-cultural acceptance in the community.

Habit of doing physical exercise was found less. Among all, only $158(27.2 \%)$ responded as they do physical exercise and out of them, only 53 (33.5\%) responded as they do physical exercise regularly $(=/>5$ times per week).

There are some limitations in the study. History of using anti-hypertensive medication was relied on the information provided by the participants without further verification, assessment of alcoholic drinks consumption was assessed just as if one consumed alcoholic beverage or not in last 12 months rather than on the basis of Standard Drinks used, and physical activity was assessed in terms of if one has habit of involvement in physical activities rather than calculating Minute Energy Consumption rate.

\section{CONCLUSIONS}

The prevalence of hypertension among adults of Kirtipur municipality was $37.0 \%$, with slight lower rate among women $(32.2 .0 \%)$ compared to men $(41.60 \%)$. Prevalence of hypertension was found increasing with advancing of age, and was found increasing with higher the BMI score. Among 215 participants having hypertension, 37.2\% was not aware that they have hypertension. Nearly onefourth $(23.5 \%)$ participants were current smokers, and 
among them $58.1 \%$ had high blood pressure, and $27.2 \%$ participants did physical exercises, but only $9.1 \%$ did regular physical exercises.

\section{ACKNOWLEDGMENTS}

This study was conducted with grant support from The University Grants Commission (UGC) Nepal.

\section{REFERENCES}

1. World Health Organization. Global Status Report on Non communicable Diseases. Geneva:WHO; 2014.[Full Text]

2. National Institutes of Health. The Seventh Report of the Joint National Committee on Prevention, Detection, Evaluation, and Treatment of High Blood Pressure. Washington DC: US Department of Health and Human Services; 2004.[Full Text]

3. Antezana FS. Epidemiologic aspects of hypertension in the world. One medicine, Two Cultures. Hypertension. Geneva:WHO; 1996.

4. World Health Organization. A Global Brief on Hypertension, Silent Killer, Global Public Health Crisis. Geneva: WHO; 2013. (Document Number: WHO/ DCO/WHD/2013.2)[Full Text]

5. Dhital SM, Karki A. Dealing with the burden of hypertension in Nepal: Current status, challenge and health system issues. Regional Health Forum. 2013; Vol 7.[Full Text]

6. Sharma SK, Ghimire A, Radhakrishnan J, Thapa L, Shrestha NR, Paudel N et al. Prevalence of Hypertension, Obesity, Diabetes, and Metabolic Syndrome in Nepal. Int J Hypertens. 2011. [Full Text]

7. Vaidya A, Pokharel PK, Karki P, Nagesh S. Exploring the iceberg of hypertension: a community based study in an Eastern Nepal town. Kathmandu Univ Med J (KUMJ). 2007;5(3):349-59.[Pub Med]

8. Dhungana RR, Devkota S, Khanal MK, GurungY, Giri RK, Parajuli RK et al. Prevalence of cardiovascular health risk behaviors in a remote rural community of Sindhuli district, Nepal. BMC Cardiovasc Disord. 2014;14:92[Full Text] .
9. Aryal KK, Mehata S, Neupane S, Vaidya A, Dhimal M, Dhakal P, et al. The Burden and Determinants of Non Communicable Diseases Risk Factors in Nepal: Findings from a Nationwide STEPS Survey. Nepal: 2015. PLoS ONE 10(8): e0134834.[Full Text]

10. Chataut J, Khanal K, Manandhar K. Prevalence and Associated Factors of Hypertension among Adults in Rural Nepal: A Community Based Study. Kathmandu Univ Med J. 2015;52(4):346-50.[Full Text]

11. Dhungana RR, Pandey AR, Bista B, Joshi S, Devkota S. Prevalence and Associated Factors of Hypertension: A community Based Cross Sectional Study in Municipalities of Kathmadnu, Nepal. International Journal of Hypertension. Volume 2016:1656938. [Full Text]

12. Manandhar K, Koju R, Sinha NP, Humagain S. Prevalence and associated risk factors of hypertension among people aged 50 years and more in Banepa Municipality, Nepal. Kathmandu Univ Med J. 2012;10(39):35-8.[Full Text]

13. World Health Organization. WHO STEP Surveillance, Training and Practical Guides to Physical Measurement Manual. Geneva:WHO; 2005.[Full Text]

14. World Health Organization. Global Database on Body Mass Index. Geneva:WHO; 2006.[Full Text]

15. Appropriate body-mass index for Asian populations and its implications for policy and intervention strategies. WHO Expert Committee, Lancet. 2004;363:157-63. [Full Text]

16. Vasan RS, Larson MG, Leip EP, Evans JC, O’Donnell CJ, Kannel WB, et al. Impact of high normal blood pressure on the risk of cardiovascular disease. N Engl J Med. 2001;345(18):1291-7.[Full Text]

17. Koju R, Manandhar K, Gurung R, Pant P, Bedi TRS. Prevalence of Hypertension in Semi-urban Area of Nepal. Nepalese Heart Journal. 2013;7(1):35-9.

18. Shakya S, Timilasina M, Timilsina K, Lamsal M, Dhakal $S$, Neupane P. Hypertension among Young Adults in the Shoping Malls of Kathmandu. Nepalese Heart Journal. 2012;9(1):33-6. 